\title{
BMJ Open Type of terrain and infant and young child feeding practices: cross-sectional study findings on children below 2 years of age from northern Bangladesh
}

\author{
Fahmida Dil Farzana, ${ }^{1}$ Nuzhat Choudhury (D) , ${ }^{1}$ Md Ahshanul Haque, ${ }^{1}$ \\ Mohammad Ali, ${ }^{1}$ Mohammad Jyoti Raihan, ${ }^{1}$ SM Tanvir Ahmed, ${ }^{2}$ \\ Sheikh Shahed Rahman, ${ }^{2}$ Towfida Jahan Siddiqua, ${ }^{1}$ Farina Naz, \\ ASG Faruque (D) , ${ }^{1}$ Tahmeed Ahmed (D) ${ }^{1}$
}

To cite: Farzana FD, Choudhury N, Haque MA, et al. Type of terrain and infant and young child feeding practices: cross-sectional study findings on children below 2 years of age from northern Bangladesh. BMJ Open 2022;12:e056593. doi:10.1136/ bmjopen-2021-056593

- Prepublication history for this paper is available online. To view these files, please visit the journal online (http://dx.doi. org/10.1136/bmjopen-2021056593).

Received 19 August 2021 Accepted 07 January 2022

Check for updates

(c) Author(s) (or their employer(s)) 2022. Re-use permitted under CC BY-NC. No commercial re-use. See rights and permissions. Published by BMJ.

${ }^{1}$ Nutrition and Clinical Services Division, icddr,b, Dhaka,

Bangladesh

${ }^{2}$ Child Poverty Sector, Save the Children Bangladesh, Dhaka, Bangladesh

Correspondence to

Dr ASG Faruque;

gfaruque@icddrb.org

\section{ABSTRACT}

Introduction 0ptimal feeding practices are vital for the subsistence, adequate nutrition, physical growth and mental development of infants and young children. This study aimed to examine the prevalence of core infant and young child feeding (IYCF) indicators and their associations with the type of terrain, that is, geographical area or zone among the beneficiaries of a large-scale nutrition programme, Suchana, being carried out in the northern part of rural Bangladesh.

Methodology A cross-sectional study was conducted from November 2016 to February 2017 in Sylhet and Moulvibazar districts of Sylhet Division, Bangladesh. Data pertaining to 5440 children aged below 24 months were analysed for this study. Univariate analysis was carried out to establish the prevalence of the indicators; selected variables were subjected to multiple regression model to identify independent relationships between the IYCF indicators and the type of terrain stratified as plain land, hilly area, flash-flood prone area and haor (wetland). Results In logistic regression analysis, flash-flood prone areas were significantly associated with higher exclusive breast feeding $(1.92,95 \% \mathrm{Cl} 1.12$ to $3.30 ; \mathrm{p}=0.019)$, minimum meal frequency $(1.45,95 \% \mathrm{Cl} 1.07$ to 1.97 ; $\mathrm{p}=0.018)$ and minimum dietary diversity $(1.63,95 \% \mathrm{Cl} 1.01$ to $2.63 ; p=0.046$ ) compared with plain land. Moreover, hilly areas were associated with significantly lower introduction of solid, semisolid or soft foods $(0.39,95 \% \mathrm{Cl} 0.18$ to 0.82 ; $\mathrm{p}=0.013$ ) compared with plain land.

Conclusion The observed prevalence of the indicators can be set as benchmark while prioritising interventions aimed at improving IYCF practices among underprivileged families residing in different types of rural setting in Bangladesh.

\section{INTRODUCTION}

Optimal feeding practices are vital for the subsistence, adequate nutrition, physical growth and mental development of infants and young children. ${ }^{1}$ These feeding practices include both breast feeding and complementary feeding and are commonly known as
Strengths and limitations of this study

- The large sample size, accurate techniques of selecting the study households and statistical methodology represent strengths of this study.

- This study was conducted on a vulnerable population, so the findings cannot be generalised to all segments of society.

- When collecting data on the infant and young child feeding practices, we had to depend solely on the respondents' responses; thus, there is a probability of introducing recall bias.

infant and young child feeding (IYCF) practices. ${ }^{1}$ Of all of the proven preventive nutrition and health interventions, optimal IYCF practices have the single greatest impact on child growth, development and survival. ${ }^{2}$ Inappropriate complementary feeding and breastfeeding practices both adversely affect children's health and growth. ${ }^{3-5}$

Infants are most susceptible to adverse health and nutrition outcomes during the transition period when complementary feeding commences. As breastmilk alone is nutritionally inadequate after the age of 6 months, a sufficient amount and appropriate diversity of complementary foods are required to support accelerated growth. ${ }^{6}$ Well-timed, sufficient and safe complementary food is required to satisfy the nutritional requirements of these children. ${ }^{7}$ In order to assess the IYCF criteria, it is crucial to explore the current prevalence of IYCF indicators that are easily measurable, accurate and reliable. Such indicators provide indispensable evidence to track improvements and guide investment from the government and other stakeholders to improve the nutrition and health of young children, particularly during 
the first 2 years of life. ${ }^{8}$ Inadequate breast feeding and complementary feeding are also mentioned as causes in the WHO's conceptual framework for childhood stunting. ${ }^{9}$ Moreover, these feeding practices should not be followed distinctly, as the features of optimal feeding at this age are multidimensional. ${ }^{8}$

The WHO suggested a set of vital indicators of child feeding practices applicable to children below 2years of age should be monitored to ensure proper nutrition and growth. ${ }^{810}$ As global public health endorsements, these core indicators emphasise the initiation of breast feeding within 1 hour of birth, exclusive breast feeding for the first 6 months of life and continued breast feeding for 2 years or more, along with the introduction of age-appropriate, nutritionally sufficient complementary feeding after 6 months of age. ${ }^{7810-12}$ Though these practices are considered compelling interventions that can boost child health, low rates of breast feeding and complementary feeding practices are observed globally. ${ }^{13}$ In many countries, fewer than one-fourth of children aged 6-23 months receive the WHO recommended serving and variety of food. ${ }^{14}$ Moreover, complementary feeding often starts too early or too late, which also leads to nutritional inadequacies. ${ }^{13}$

Poor IYCF practices are the dominant factors contributing to the high rates of child undernutrition in low-income and middle-income countries, ${ }^{1516}$ and Bangladesh is no exception. Childhood undernutrition is more prevalent among the poorest socioeconomic segments of the population. ${ }^{17}$ Additionally, living in a vulnerable location such as a haor (wetland) or flood-prone or hilly areas may negatively influence appropriate IYCF practices compared with living on plain land. Due to the lack of studies on the effect of the type of terrain on IYCF practices in the Bangladeshi context, the objective of this article was to examine the prevalence of the WHO's core recommended IYCF practice indicators and their associations with the type of terrain (haor (wetland), floodprone, hilly area and plain land) among the beneficiaries of the Suchana programme in rural northeast Bangladesh. ${ }^{18}$ Suchana is a large-scale nutrition programme working with the poor and vulnerable population in this region to improve their livelihood options. The findings of this study are expected to provide additional evidence to promote IYCF practices by enabling intervention activities to be more precisely tailored to the geographical setting. ${ }^{19}$

\section{METHODS}

\section{Study design}

This cross-sectional study analysed data derived from the database of the baseline survey of a larger clusterrandomised pre-post study, which was conducted to evaluate the performance of the Suchana programme, ${ }^{18}$ a comprehensive programme designed to improve the nutritional status of children targeting the poorest segment of the population in northeast Bangladesh.

\section{Study area}

The study area consists of Sylhet and Moulvibazar districts of Sylhet Division, Bangladesh. In total, 640 villages from 80 unions in these districts were surveyed.

\section{Study population}

Data pertaining to 5440 children aged below 24 months were analysed. During data collection, special attention was given to child-feeding practices. Information was collected through a 24-hour recall questionnaire administered by trained interviewers targeting the previous 24 hours, as widely used and considered appropriate for surveys seeking information on IYCF practices. ${ }^{8}$ The selection procedure of the household is mentioned further.

First, two districts (ie, Sylhet and Moulvibazar) of Sylhet division, where no other major large-scale maternal and nutrition programmes are being implemented, were selected for Suchana. Then all sub-districts, except for tea gardens and a small number of urban areas, within these two districts were divided into four phases in a randomised manner. In the baseline study, phase-I and phase-IV areas were surveyed. From the pool of 157 unions, 40 random unions were allocated to phase-IV and another 40 unions were allocated to phase-I.

Second, within each union, villages were listed based on vulnerability (eg, frequency of flooding/submerging, low or no intervention by development programmes, poverty/ household living situation, remoteness/difficulty to reach and superstitions/high prevalence of social taboos) after discussion with local government officials, elected representatives, local elites and field visits. Suchana consortium staff members from local offices within these districts selected the poorest communities within their area. Eight villages from each union were chosen for baseline evaluation.

Third, field staff used a combination of a participatory approach, especially wealth ranking methods, a series of focus group discussions and individual interviews with different local people, to identify the very poor households to be targeted in each community. Through a participatory rural appraisal, households were allocated to one of four community-defined wealth groups. The households who were ranked in the bottom two of the wealth groups were visited by field staff to determine whether or not they meet the programme selection criteria for enrolment in Suchana. Based on the criteria, sampling frame was made. Using this frame, we carried out household selection via probability sampling approach using systematic sampling method.

\section{Duration of the study}

The Suchana baseline survey data were collected from November 2016 to February 2017.

\section{Variables of interest}

The variables of interest included core IYCF indicators consistent with the WHO guidelines: (1) early initiation of breast feeding (children born in the last 2 years 
being placed on their mother's breast within an hour after delivery); (2) exclusive breast feeding (EBF) under 6 months (infants under 6 months given only breastmilk and no other food); (3) continued breast feeding at 1 year (children aged between 12 and 15 months who are still breast fed); (4) introduction to solid, semi-solid or soft foods (introduction of solid, semisolid or soft foods to infants aged between 6 and 8 months); (5) minimum dietary diversity (MDD); (6) minimum meal frequency (MMF); (7) minimum acceptable diet (MAD); and (8) consumption of iron rich/fortified foods. ${ }^{10}$

MDD is defined as children between 6 and 23 months old being fed foods from at least four of the seven food groups: (1) food made from cereal grains, roots and tubers; (2) legumes such as beans and peas, and nuts; (3) milk and other dairy products; (4) meat; (5) eggs; (6) foods rich in vitamin A; and (7) fruits and vegetables. MMF is defined as achieving the minimum number of feeds (or more) for both breastfed and non-breastfed children aged between 6 and 23 months who have been introduced to solid, semisolid or soft foods (this includes milk feeds for non-breastfed children). MAD was defined as a combination of MMF and MDD for children aged between 6 and 23 months of age. Consumption of ironrich/iron-fortified food was assessed as the proportion of children aged between 6 and 23 months who are given iron-rich food or food fortified with iron specially prepared for infants and young children, or food fortified with iron at the household level.

The Household Food Insecurity Access Scale was used to define food insecurity according to the Food and Nutrition Technical Assistance's guidelines to provide a constant assessment of the degree of food insecurity (access component) at the household level. ${ }^{20}$ This scale identifies the level of food insecurity based on a lack of access to food due to poverty, not due to shortage of supply of food. ${ }^{20}$ The level of anxiety and uncertainty of the participants regarding household food resources, satisfaction about the nature of the food and inadequacy of food consumption experienced were assessed using a standard nine-question questionnaire which inquires about worrying about food, inability to eat preferred foods, the lack of food diversity in diet, having to eat food that they dislike, eating less food than needed, consuming fewer meals in a day, not having food at home, going to bed hungry and not eating food for a whole day and night. ${ }^{21} 22$

Programme workers who had been working in the areas for a significant period of time classified the locations of each household based on the type of terrain as follows: haor (wetland), flash-flood prone area, hilly area and plain land. These were practically categorised.

\section{Analysis}

In this analysis, data on children aged below 24 months were assessed. Stata V.14 (Stata Corporation, College Station, TX, USA) was used for statistical analyses. Variables relevant to the analysis were selected after consulting previous survey questionnaires and demographic and health survey questionnaires. Various statistical plots were used for data visualisation. Descriptive statistics such as means and SD, and frequencies and proportions were calculated to assess the distribution of the data. The primary analysis involved producing descriptive statistics using appropriate cut-off values for different variables. Simple logistic regression analysis was performed to investigate the bivariate relationships between the IYCF practices and the type of terrain and other variables. Finally, the strength of the associations was determined by calculating adjusted ORs and 95\% CIs using multiple logistic regression. Multicollinearity was checked after estimating the variance inflation factor using Stata Collin command. Statistical significance was defined as a $p$ value of $<0.05$.

\section{Patient and public involvement}

Patients and the public were not actively involved in formulating the research question and protocol development, including the outcome measures. However, for smooth operation of the field works, local elites/influential persons, for example, teachers, religious persons and local government council members were informed about the study.

\section{RESULTS}

Table 1 presents the descriptive statistics for the study population. The mean age of the children was 13 months; around $49 \%$ of children were female. Mean maternal age was around 27 years; maternal age at first marriage and first pregnancy were 18 and 19 years, respectively. Around $23 \%$ of respondents had 1 year of formal schooling. Fifteen percent of respondents had received the standard number of four antenatal care visits during their last pregnancy; about $84 \%$ had a normal delivery for their last pregnancy. Seventeen percent of women reported having decision-making power on certain household activities (decision-making activities: (1) major household purchases, (2) food purchases, (3) food preparation, (4) own healthcare, (5) children's healthcare and (6) visiting family and relatives). The mean household size was 6.3; $96 \%$ of household heads were male and around $51 \%$ had at least 1 year of formal education. More than $90 \%$ of the respondents were Muslim. Only $14 \%$ of households were food secure.

Figure 1 presents the prevalence of the core IYCF indicators stratified by the type of terrain. The rate of exclusive breast feeding ranged from $60 \%$ to $75 \%$, with the highest prevalence in flash-flood prone areas. Early initiation of breast feeding ranged from $85 \%$ to $88 \%$, with the highest prevalence among children from haor areas. The prevalence of continued breast feeding at 1 year was 98\% in hilly areas. Around $83 \%$ of children from plain lands were introduced to solid and semi-solid foods at an appropriate age (6-8 months). MDD was attained by $16 \%$ of children from flash-flood prone and hilly areas. MMF was observed for $51 \%$ of children, and a MAD was reported for $13 \%$ of children from flash-flood prone 
Table 1 General characteristics

\section{Indicator}

Child's characteristics

Age (months) ${ }^{\star}$

Female sex

Maternal characteristics

\section{Age (years)*}

Age at first marriage*

Age at first pregnancy ${ }^{*}$

Maternal education

No schooling

At least 1 year of formal education

Antenatal care check-ups

Less than four

At least four

814

26.89

18.23

19.32

4191

1249

4626

Number of children

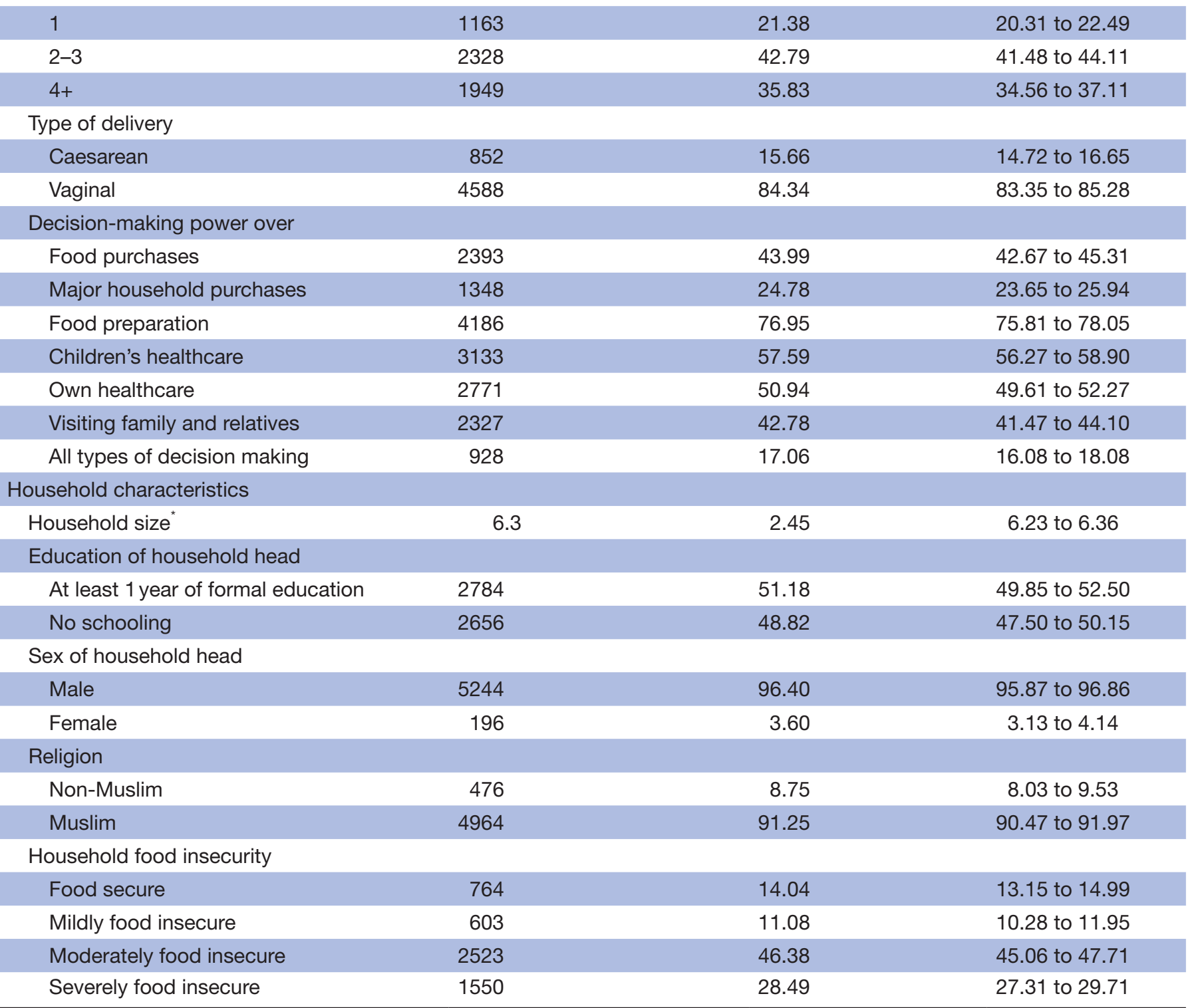

${ }^{*}$ Mean \pm SD.

\section{Percentage/SD $\quad 95 \% \mathrm{Cl}$}

$\begin{array}{rr}6.41 & 13.22 \text { to } 13.56 \\ 49.06 & 47.73 \text { to } 50.27\end{array}$

5.64

26.74 to 27.04

2.73

18.16 to 18.31

2.94

19.25 to 19.40

75.90 to 78.14

21.86 to 24.10

22.96

84.06 to 85.96

85.04

14.04 to 15.94

14.96 


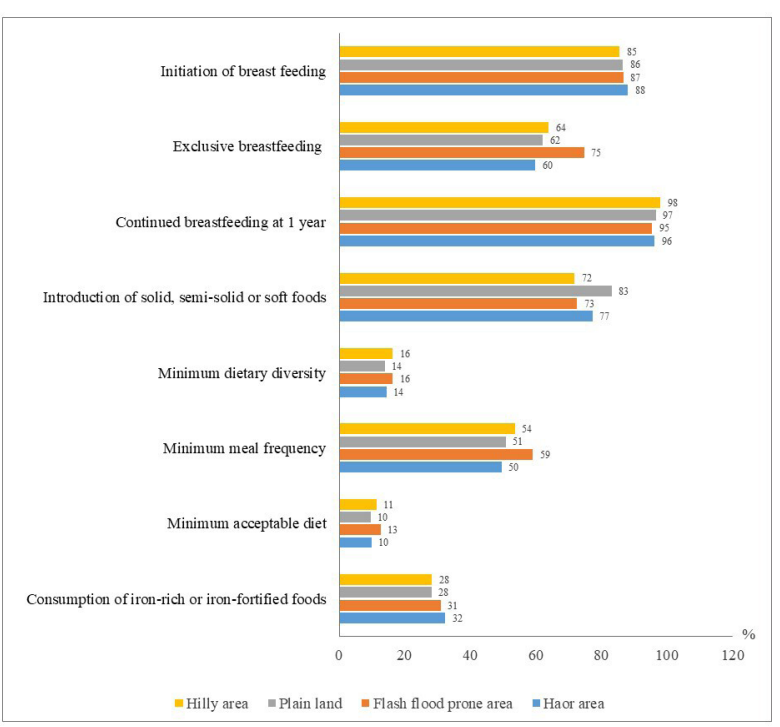

Figure 1 Distribution of infant and young child feeding indicators by type of terrain.

areas. Consumption of iron-rich food during last 24 hours preceding the interview was observed for $32 \%$ of children in haor areas.

Table 2 presents the associations between the IYCF indicators and the type of terrain. Four of the eight core indicators were significantly associated with the type of terrain. Compared with the plain land, flash-flood prone areas were associated with significantly better odds of exclusive breast feeding (1.92, 95\% CI 1.12 to 3.30 ; $\mathrm{p}=0.019), \operatorname{MMF}(1.45,95 \%$ CI 1.07 to $1.97 ; \mathrm{p}=0.018)$ and MAD (1.63, 95\% CI 1.01 to $2.63 ; \mathrm{p}=0.046)$. However, hilly areas were associated with a significantly lower odds of introduction of solid, semi-solid or soft foods $(0.39,95 \%$ CI 0.18 to $0.82 ; \mathrm{p}=0.013$ ) compared with plain land.

\section{DISCUSSION}

Here, we analysed data generated in the Suchana baseline survey (which employed a cross-sectional design) to examine the prevalence of WHO-recommended core IYCF indicators and their associations with the type of terrain among potential beneficiaries of the Suchana intervention in rural Bangladesh. The results indicated that, compared with children living in plain lands, children living in flash-flood prone areas were significantly more likely to achieve EBF, MMF and MAD. In contrast, children in hilly areas were significantly less likely to be introduced to solid and semi-solid foods at an appropriate age.

In this study of a vulnerable population in northeast Bangladesh, four of the eight core IYCF indicators (EBF; initiation of solid, semi-solid and soft foods; MMF; MAD) were significantly related to the type of terrain. A small number of studies reported that the feeding practices of children vary with the geographical setting. ${ }^{23} 24$ Geographical differences have also been denoted as one of the variables associated with inappropriate complementary feeding practices among children aged 6-23 months in low-income countries. ${ }^{17}$ Similarly to our study, the area of residence (urban) was described as a key element of EBF in a study conducted in Ethiopia. ${ }^{31}$ A study in India found MMF and MAD were related with area of residence comparable to our study. ${ }^{5}$ A number of community-based cross-sectional studies from India demonstrated significant associations between MAD and the area of residence, ${ }^{531}$ similar to this analysis.

A systematic review of data on children below 2 years of age from Bangladesh reported living in a flood-prone area was an impediment to IYCF practices. ${ }^{32}$ In contrast, we observed higher rates of EBF, MMF and MAD practices in flood-prone areas compared with the other areas.

Table 2 Strength of associations between the IYCF indicators and the type of terrain using plain land as the reference

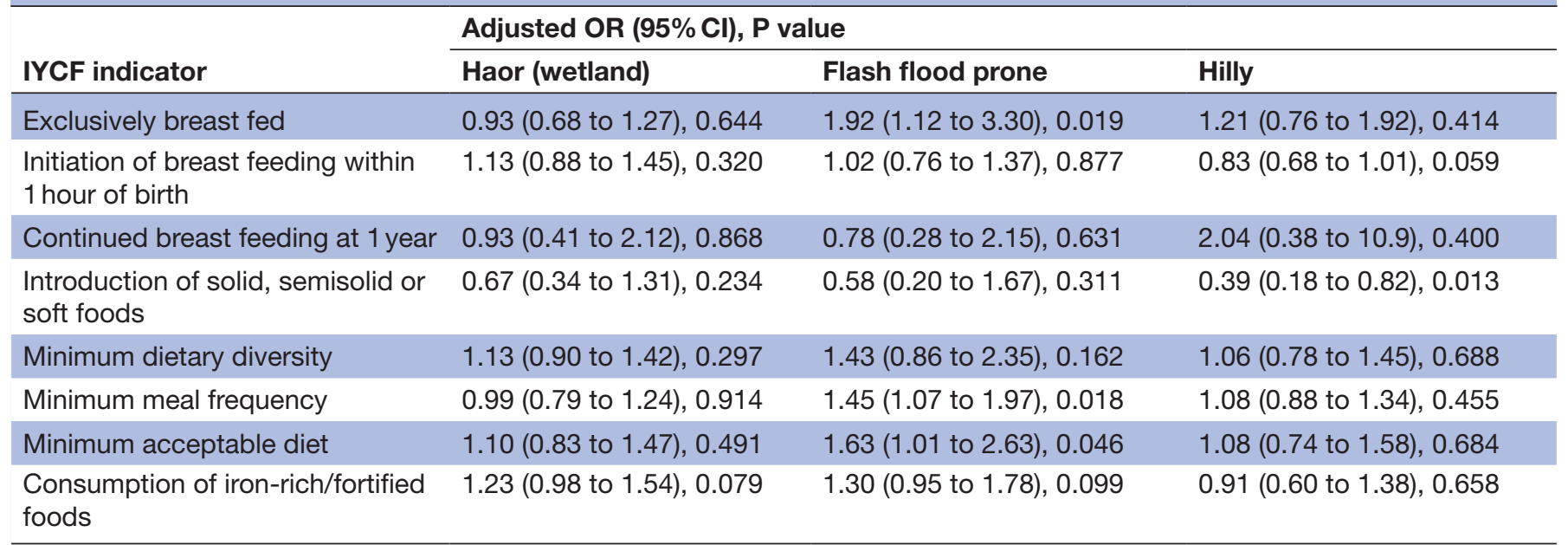

Adjusted for child's sex and age, maternal age at marriage, education, number of children, antenatal care, maternal nutritional status, type of delivery, experience of any domestic violence, decision-making power, the educational level of the $\mathrm{HH}$ head, the sex of $\mathrm{HH}$ head, the age of $\mathrm{HH}$ head, $\mathrm{HH}$ size, HFIAS and $\mathrm{HH}$ asset index. Clusters were adjusted.

HFIAS, Household Food Insecurity Access Scale; HH, household; IYCF, infant and young child feeding. 
Mothers of flash-flood prone areas were well motivated possibly, particularly from their late pregnancy for practising high rates of exclusive breast feeding, though breast feeding at 1 year was not optimum (not statistically significant though), which could be due to their involvement in agricultural or other wage-earning activities. Additionally, these discrepancies could be attributed to the differences in the feeding habits and purchasing power of households in specific types of terrain. Lower dietary diversity that impacted MAD has been reported for living in rural compared with those in urban Nepal; this may have been influenced by household food insecurity status and traditional beliefs and practices regarding food consumption. For example, in rural communities in Nepal, vegetables and fruits are considered hazardous to the health of infants and young children because these foods are regarded as 'cold foods'. ${ }^{33}$ Similar to this analysis, mothers' knowledge on the timing and importance of IYCF, and IYCF practices may be of suboptimum level, which may be related to the cultural background of the household as well as the community. The study also mentioned the existence of widespread misconceptions that less than 1-year-old infants are unable to digest food from animal sources. ${ }^{25}$

Seasonal and agroecological variations in IYCF practices among children aged 6-23 months were observed in Ethiopia due to the fact that food availability and access in the country are strongly affected by seasonality. ${ }^{30}$ At the household level, attributing factors such as the participation of women in agricultural activities often reduces the time available to mothers for the care of infants and young children. Furthermore, among communities that primarily rely on production of cash crops, their selling of the products results in ready purchase of food stuffs for the household. Some communities also produce vegetables and fruits, which to an extent are consumed at the household level. This could be the possible reason for not practising timely initiation of solid and semisolid foods by the mothers belonging to hilly areas; may be due to their increasing commitments in agricultural activities in the field, wage-earning doings as day labourer or family commitments, they failed to introduce solid/semi-solid foods to their children in due time.

Geographical variations in dietary diversity in Indonesia have been related to different food cultures or beliefs about the types of foods that are suitable for infants and young children and the availability of these foods, and these factors negatively impact MAD ${ }^{26}$ In India, food insecurity in the poorest households and traditional barriers in households in the middle wealth quintile were identified as factors for children not attaining MAD. The factors that consistently impacted inappropriate IYCF practices were a low-level schooling of the mother, a low frequency of antenatal visits and lack of exposure to media. ${ }^{29}$

Complementary feeding is frequently not initiated at an appropriate age: children may be fed irregularly and the nutritional quality of the complementary food is low-grade, which does not support optimal growth and development. ${ }^{34}$ Nutrition interventions can encourage the adoption of conventional food preparations within communities and can also improve the recipe by incorporating additional locally accessible and culturally acceptable foods with a high nutritive value. ${ }^{35}$ Previous interventions aiming to increase IYCF knowledge and increase appropriate practice of mothers should suit well in remote rural areas ${ }^{31} 36$ to make it easy and encouraging for them. Furthermore, nutrition interventions that aim to promote child feeding should also involve other household members beyond the mothers, including the fathers and grandparents of the children; these individuals contribute largely to the family income, take the lead in decisions at the household level and have authority over their children's well-being. ${ }^{37}$

Inadequate IYCF practices have been identified as one of the most imperative proximal elements that contribute to the high burden of child malnutrition in Bangladesh. Large-scale interventions to promote the improvements in the crucial factors associated with undernutrition in Bangladesh, such as IYCF practices, are urgently required to accelerate the reduction in undernutrition. ${ }^{1438}$ Welldesigned, well-implemented, large-scale interventions that involve interpersonal and mass communication and strategic use of resources have great potential to rapidly improve IYCF practices. ${ }^{14}$ In this regard, the framework of the Suchana programme-a large-scale nutrition programme that aims to improve the nutritional status of children belonging to the lowest socioeconomic rural segment of Bangladesh-stresses the importance of key IYCF practices. One of the mandates of the Suchana programme is to enhance IYCF practices and also establish a better system to maintain these integral improvements. As the prevalence of the IYCF indicators did not considerably vary between the various types of terrain in this analysis, the programme does not need to adopt specific approaches for each area; rather a comprehensive approach will be suitable. Furthermore, access to adequate nutrition, together with cooperation from the family to facilitate optimal feeding practices, is a basic right that should be secured and promoted for every child. ${ }^{39}$

One of the explicit purposes of the global strategy for IYCF is to construct an environment that will allow mothers, families and other caregivers to choose and apply conversant options about ideal feeding practices for infants and young children in all situations ${ }^{39}$; these principles have also been adopted within the implementation strategy of the Suchana intervention. Nutrition interventions are not only about health; while consolidating local food habits, this ensures the contentment of the child and convenience for the mother. ${ }^{40}$ Moreover, the widespread availability of quality diets for children has been acknowledged to be an imperative part of the wider economic policy approaches for the future economic growth and development of a nation. ${ }^{36}$

The large sample size, and accurate techniques of selecting the study households and quality of statistical 
methodology represent strengths of this study. The study selected only households that had children below 2 years of age. The study area included, purposively selected only two of the four districts of Sylhet region. Moreover, only vulnerable populations were studied. Thus, the results may not be representative of the marginalised population of the entire region, and findings cannot be generalised to all segments of the society. Because of its cross-sectional nature and the absence of longitudinal follow-up or cohort design, the study is grossly lacking any changes that may have occurred during the entire study period. When collecting data on the IYCF practices, we had to depend solely on the respondents' responses; thus, there is a probability of introducing recall bias. Nonetheless, all attempts were made to minimise bias by providing a 4-week specific training to our data collectors on interview techniques for questions that could be subject to recall bias.

\section{CONCLUSIONS}

The current study demonstrated associations between four core IYCF indicators and the type of terrain. The prevalence of the core indicators could be set as benchmarks when planning future interventions to improve IYCF practices among underprivileged populations in rural Bangladesh. However, it should be noted that the full set of indicators should be considered for programmatic purposes. It should also be emphasised that context-specific and evidence-based indicators of IYCF intervention are included in and supported by the national policy.

Acknowledgements This article is based on data during the Suchana baseline survey; this intervention is being implemented by Save the Children, with support from the Foreign, Commonwealth and Development Office (FCDO) and the European Union (EU). The International Centre for Diarrhoeal Disease Research, Bangladesh (icddr,b) acknowledges with gratitude the commitment of Save the Children, the FCDO and the EU to its research efforts. We acknowledge with gratitude the commitment of the Government of the People's Republic of Bangladesh to icddr,b's research strength. We also acknowledge the following donors for providing unrestricted support to icddr,b's effort and advancement of its strategic plan: Canada (Department of Foreign Affairs, Trade and Development), Sweden (Sida) and the UK (FCDO). We gratefully acknowledge our core donors for their support and commitment to icddr,b's research efforts. We would like to acknowledge the invaluable contributions of Save the Children as lead agency, the technical partners Helen Keller International, World Fish and International Development Enterprises and the implementing partners Friends In Village Development Bangladesh, Rangpur Dinajpur Rural Services and the Centre for Natural Resource Studies, which played critical roles in the study.

Contributors MAH conceptualised the manuscript. MAH, FDF, MA and MJR performed statistical analysis. FDF drafted the manuscript. ASGF, TA, NC, TJS, FN, SMTA and SSR critically reviewed the scientific content of the manuscript. All authors contributed to the revision of the final draft before submission, read and approved the final version, and are responsible for the final content of this article.

Funding This work was supported by Foreign, Commonwealth and Development Office (grant/project number 204131-103).

Competing interests None declared.

Patient and public involvement Patients and/or the public were not actively involved in the design, conduct, reporting or dissemination plans of this research. Refer to the Methods section for further details.

Patient consent for publication Consent obtained from parent(s)/guardian(s).
Ethics approval This study was approved by the Research Review Committee and the Ethical Review Committee, the two obligatory components of the institutional review board of the icddr,b. Written informed consent was obtained from all study participants. The enumerator informed each respondent about the purpose of the study by reading the consent form aloud at the beginning of each interview. The respondents were also informed of the voluntary nature of their participation, the maintenance of their confidentiality and their right to withdraw from the study at any point during the interview. The identities of the respondents were not used while analyzing the data.

Provenance and peer review Not commissioned; externally peer reviewed.

Data availability statement Data are available upon reasonable request. All data relevant to the study are included in the article or uploaded as supplemental information. The data of this study on which the findings are based upon, are available on request from the corresponding author. The data are not publicly available due to privacy or ethical restrictions.

Open access This is an open access article distributed in accordance with the Creative Commons Attribution Non Commercial (CC BY-NC 4.0) license, which permits others to distribute, remix, adapt, build upon this work non-commercially, and license their derivative works on different terms, provided the original work is properly cited, appropriate credit is given, any changes made indicated, and the use is non-commercial. See: http://creativecommons.org/licenses/by-nc/4.0/.

ORCID iDs

Nuzhat Choudhury http://orcid.org/0000-0001-8345-5278

ASG Faruque http://orcid.org/0000-0001-8343-4653

Tahmeed Ahmed http://orcid.org/0000-0002-4607-7439

\section{REFERENCES}

1 Wiesmann Det al. Validation of the world food programme $s$ food consumption score and alternative indicators of household food security. Intl Food Policy Res Inst, 2009.

2 UNICEF D. Infant and young child feeding. Nutrition section, programmes. New York: UNICEF, 2011.

3 Saha KK, Frongillo EA, Alam DS, et al. Appropriate infant feeding practices result in better growth of infants and young children in rural Bangladesh. Am J Clin Nutr 2008;87:1852-9.

4 Hop LT, Gross R, Giay T, et al. Premature complementary feeding is associated with poorer growth of Vietnamese children. $J$ Nutr 2000;130:2683-90.

5 Ahmad I, Khalique N, Khalil S, et al. Complementary feeding practices among children aged 6-23 months in Aligarh, Uttar Pradesh. J Family Med Prim Care 2017;6:386.

6 Wondu Garoma B, Yang N. Determinants of suboptimal complementary feeding practices among children aged 6-23 months in selected urban slums of Oromia zones (Ethiopia). J Nutr Food Sci 2017;7:2.

7 World Health Organization, UNICEF. Global strategy for infant and young child feeding, 2003.

8 World Health Organization. Indicators for assessing infant and young child feeding practices: part 2: measurement, 2010.

9 WHO. The healthy growth project: promoting healthy growth and preventing childhood stunting, 2017.

10 WHO. Indicators for assessing infant and young child feeding practices Part 3 country profiles, W. press, editor. Geneva: WHO, 2010.

11 Wood B. Effect of breastfeeding on infant and child mortality due to infectious diseases in less developed countries: a pooled analysis. who Collaborative study team on the role of breastfeeding on the prevention of infant mortality. Lancet 2000;355:451-5.

12 WHO. Infant and young child nutrition: situation analysis and prospects in the African region. Africa, 2001.

13 World Health Organization. Model chapter for textbooks for medical students and allied health professionals. infant and young child feeding, 2009. Available: http://apps. who. int/iris/ bitstream/10665/44117/1/9789241597494_eng. pdf

14 Sanghvi T, Haque R, Roy S, et al. Achieving behaviour change at scale: Alive \& Thrive's infant and young child feeding programme in Bangladesh. Matern Child Nutr 2016;12(Suppl 1):141-54.

15 Rakotomanana H, Gates GE, Hildebrand D, et al. Situation and determinants of the infant and young child feeding (IYCF) indicators in Madagascar: analysis of the 2009 demographic and health survey. BMC Public Health 2017;17:812.

16 Das N, Chattopadhyay D, Chakraborty S, et al. Infant and young child feeding perceptions and practices among mothers in a rural area of West Bengal, India. Ann Med Health Sci Res 2013;3:370-5. 
17 Kabir I, Khanam M, Agho KE, et al. Determinants of inappropriate complementary feeding practices in infant and young children in Bangladesh: secondary data analysis of demographic health survey 2007. Matern Child Nutr 2012:8(Suppl 1):11-27.

18 Choudhury N, Raihan MJ, Ahmed SMT, et al. The evaluation of Suchana, a large-scale development program to prevent chronic undernutrition in north-eastern Bangladesh. BMC Public Health 2020;20:1-9.

19 Vyas S, Kandpal SD, Semwal J, et al. Trends in weaning practices among infants and toddlers in a hilly terrain of a newly formed state of India. Int J Prev Med 2014;5:741.

20 Diaz-Bonilla E, Robinson S. Shaping globalization for poverty alleviation and food security. International Food Policy Research Institute (IFPRI), 2001.

21 Coates J, Swindale A, Bilinsky P. Household food insecurity access scale (HFIAS) for measurement of food access: indicator guide. Washington, DC: Food and Nutrition Technical Assistance Project, Academy for Educational Development, 2007: 34.

22 Haque MA, Farzana FD, Sultana S, et al. Factors associated with child hunger among food insecure households in Bangladesh. BMC Public Health 2017;17:205.

23 Padmanabhan PS, Mukherjee K. Infant and young child feeding (IYCF): a gap analysis between policy and practice. The 2nd International Conference on Public Health, Colombo, Sri Lanka; 2829 July, 2016, 2016

24 Gewa CA, Leslie TF. Distribution and determinants of young child feeding practices in the East African region: demographic health survey data analysis from 2008-2011. J Health Popul Nutr 2015;34:6.

25 Joshi N, Agho KE, Dibley MJ, et al. Determinants of inappropriate complementary feeding practices in young children in Nepal: secondary data analysis of demographic and health survey 2006. Matern Child Nutr 2012;8(Suppl 1):45-59.

$26 \mathrm{Ng}$ CS, Dibley MJ, Agho KE. Complementary feeding indicators and determinants of poor feeding practices in Indonesia: a secondary analysis of 2007 demographic and health survey data. Public Health Nutr 2012;15:827-39.

27 Hazir T, Senarath U, Agho K, et al. Determinants of inappropriate timing of introducing solid, semi-solid or soft food to infants in Pakistan: secondary data analysis of demographic and health survey 2006-2007. Matern Child Nutr 2012;8(Suppl 1):78-88.

28 Senarath U, Godakandage SSP, Jayawickrama H, et al. Determinants of inappropriate complementary feeding practices in young children in Sri Lanka: secondary data analysis of demographic and health survey 2006-2007. Matern Child Nutr 2012;8(Suppl 1):60-77.

29 Patel A, Pusdekar Y, Badhoniya N, et al. Determinants of inappropriate complementary feeding practices in young children in India: secondary analysis of national family health survey 2005-2006. Matern Child Nutr 2012;8(Suppl 1):28-44.

30 Roba KT, O'Connor TP, Belachew T, et al. Variations between postand pre-harvest seasons in stunting, wasting, and infant and young child feeding (IYCF) practices among children 6-23 months of age in lowland and midland agro-ecological zones of rural Ethiopia. Pan Afr Med J 2016;24:163.

31 Tariku A, Alemu K, Gizaw Z, et al. Mothers' education and ANC visit improved exclusive breastfeeding in Dabat health and demographic surveillance system site, Northwest Ethiopia. PLoS One 2017;12:e0179056.

32 Manikam L, Robinson A, Kuah JY, et al. A systematic review of complementary feeding practices in South Asian infants and young children: the Bangladesh perspective. BMC Nutr 2017;3:56.

33 Parashar A, Sharma D, Thakur A, et al. Infant and young child feeding practices - insights from a cross-sectional study in a hilly state of North India. Int J Nutr Pharmacol Neurol Dis 2015;5:103.

34 Victor R, Baines SK, Agho KE, et al. Factors associated with inappropriate complementary feeding practices among children aged 6-23 months in Tanzania. Matern Child Nutr 2014;10:545-61.

35 Roche ML, Gyorkos TW, Blouin B, et al. Infant and young child feeding practices and stunting in two highland provinces in Ecuador. Matern Child Nutr 2017;13:e12324.

36 UNICEF. Programming Guide - Infant and Young Child Feeding. IYCF Unit, Nutrition section, UNICEF New York: New York, 2012.

37 CARE. Nutrition at the center, integrated programming to maximize human potential, Bangladeh formative research report, 2013.

38 Haque Ret al. Alive \& Thrive: expanding community interventions to improve nutrition in Bangladesh. Scaling up in agriculture, rural development, and nutrition. Washington DC: International Food Policy Research Institute, 2012: 10. 22-3.

39 World Health Organization, UNICEF. Planning guide for national implementation of the global strategy for infant and young child feeding 2007.

40 Kayser O, Klarsfeld L, Brossard S. Marketing nutrition for the base of the pyramid. Paris: Hystra, 2014. 